\title{
ARDUINO DAN MODUL WIFI ESP8266 SEBAGAI MEDIA KENDALI JARAK JAUH DENGAN ANTARMUKA BERBASIS ANDROID
}

\author{
S. Samsugi ${ }^{1)}$, Ardiansyah ${ }^{2)}$, Dyan Kastutara ${ }^{1)}$ \\ ${ }^{1)}$ Informatika, FTIK, Universitas Teknokrat Indonesia, Bandar Lampung, Indonesia 35142 \\ ${ }^{2)}$ Program Studi Ilmu Komputer, FMIPA, Universitas Lampung, Bandar Lampung, Indonesia 35145 \\ 1) s.samsugi@teknokrat.ac.id, ${ }^{2)}$ ardiansyah.unila@gmail.com
}

\begin{abstract}
Abstrak
Energi listrik merupakan salah satu kebutuhan pokok yang sangat penting bagi kehidupan manusia saat ini, hampir setiap kegiatan yang dilakukan manusia berhubungan dengan energi listrik. Perkembangan teknologi dibidang elektronika saat ini membuat pola pikir manusia semakin kedepan dalam penerapan peralatan elektronika.Teknologi elektronika yang dapat mengendalikan peralatan elektronik rumah tangga dari jarak jauh salah satunya teknologi internet of things. Teknologi lain yang dikembangkan adalah teknologi yang bertujuan untuk menghemat energi listrik yang digunakan pada rumah tangga. Internet of Things didefinisikan sebagai interkoneksi dari perangkat komputasi tertanam (embedded computing devices) yang teridentifikasi secara unik dalam keberadaan infrastruktur internet. Sistem kendali pada penelitian ini dirancang menggunakan Arduino UNO dengan mikrokontroler ATmega328 sebagai pusat kendali dari sistem, serta modul wifi ESP8266 guna untuk komunikasi kontroler ke internet melalui media wifi. Interface dibuat dengan berbasis Android.
\end{abstract}

Kata kunci: energi listrik, internet of things, Arduino, modul wifi esp8266

\section{Pendahuluan}

Energi listrik merupakan salah satu kebutuhan pokok yang sangat penting bagi kehidupan manusia saat ini, hampir setiap kegiatan yang dilakukan manusia berhubungan dengan energi listrik. Perkembangan teknologi dibidang elektronika saat ini membuat pola pikir manusia semakin kedepan dalam penerapan peralatan elektronika. Salah satu yang dikembangkan adalah teknologi elektronika yang dapat mengendalikan peralatan elektronik rumah tangga dari jarak jauh. Internet of Things didefinisikan sebagai interkoneksi dari perangkat komputasi tertanam (embedded computing devices) yang teridentifikasi secara unik dalam keberadaan infrastruktur internet. Internet of Things adalah sebuah konsep komputasi yang menggambarkan masa depan dimana setiap obyek fisik dapat terhubung dengan internet dan dapat mengidentifikasi dengan sendirinya antar perangkat lain Sulistyanto et al [1].

Berdasarkan permasalahan tersebut, dilakukanlah penelitian terhadap pengembangan sistem kendali jarak jauh yang dapat mengendalikan perangkat elektronik rumah tangga melalui media internet. Pengembangan sistem kendali ini bertujuan untuk mengontrol alat elektronik rumah agar energi listrik yang digunakan tidak berlebihan sehingga menyebabkan pengeluaran biaya yang tinggi.

Sistem kendali ini dirancang menggunakan Arduino UNO dengan mikrokontroler ATmega328 sebagai pusat kendali dari sistem, serta modul wifi ESP8266 guna untuk komunikasi kontroler ke internet melalui media wifi [2]. Penelitian ini difokuskan pada mengendalikan lampu dari jarak jauh. Aplikasi antarmuka dibuat dengan menggunakan HTML5.

\section{Pembahasan}

A. Analisa Kebutuhan Hardware dan Software

Bahan dan peralatan yang dibutuhkan dalam pembuatan sistem kendali jarak jauh berbasis Arduino dengan modul WiFi ESP8266 pada aplikasi Internet of Things (IoT) meliputi Hardware (Perangkat Keras) berupa Arduino UNO, Modul WiFi ESP8266 - 01, Modul Relay 4 channel, Mini Router (Modem) Andromax M2Y, Smartphone ASUS Zenfone 4, Catu Daya / Adaptor 12 Volt, Power Supply 3,3v / 5v YwRobot, Breadboard, Kabel Jumper, Fitting Lampu, dan Lampu. Software (Perangkat Lunak) terdiri dari Arduino IDE, Fritzing, Sublime Text / Adobe Dreamweaver.

\section{B. Metode Pengumpulan Data}

Metode pengumpulan data yang biasa digunakan diantaranya adalah wawancara, survey langsung ke lapangan, membaca manual atau blueprint dokumentasi, menelaah setiap data yang didapat dari data-data sebelumnya. Metode pada laporan penelitian yang dilakukan dalam membuat sistem kendali jarak jauh berbasis Arduino menggunakan modul WiFi ESP8266 pada aplikasi Internet of Things yaitu dengan melakukan studi pustaka dengan cara mencari dan mengumpulkan data-data obyek yang akan dibuat melalui buku-buku, tesis dan jurnal-jurnal ilmiah, maupun dari internet.

\section{Jalannya Penelitian}

Penelitian yang dilakukan dalam membuat sistem kendali jarak jauh berbasis Arduino menggunakan modul WiFi ESP8266 pada aplikasi Internet of Things. 


\section{Perancangan Sistem Kendali}

Bagian ini penulis menjelaskan bagaimana merancang sistem kendali jarak jauh dengan menggunakan teknologi internet of things. Sistem kendali jarak jauh yang akan dirancang dapat digambarkan dengan diagram pada gambar 1

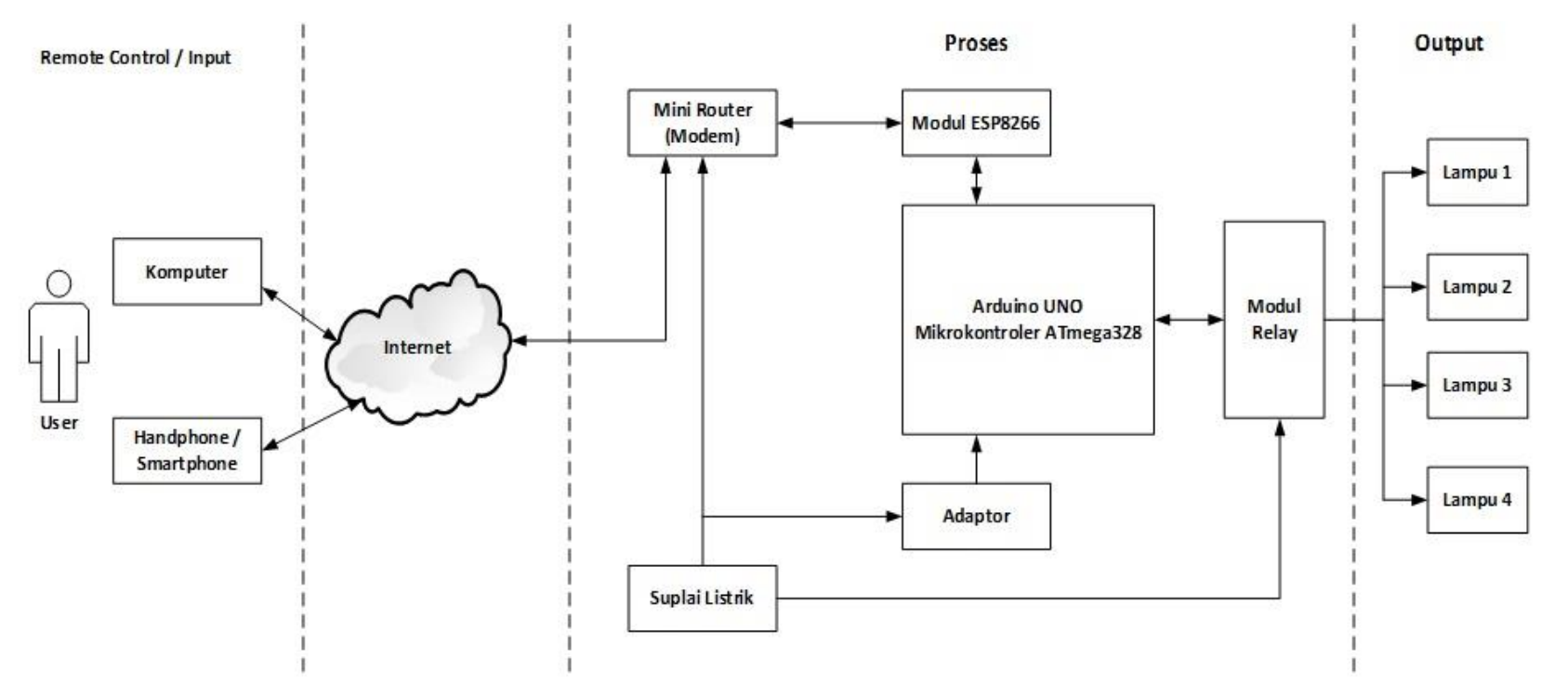

\section{Gambar 1 Sistem kendali jarak jauh}

E. Perancangan Antarmuka Berbasis Android

Pada tahapan ini adalah membangun purwarupa (prototype) pengendalian perangkat elektronik rumah tangga dan sistem IoT pada platform Android. Gambar 2 berikut menunjukan purwarupa yang telah dikembangkan. Melalui antar muka android dimaksudkan dapat melakukan pengendalian terhadap perangkat AC dan Lampu [3].

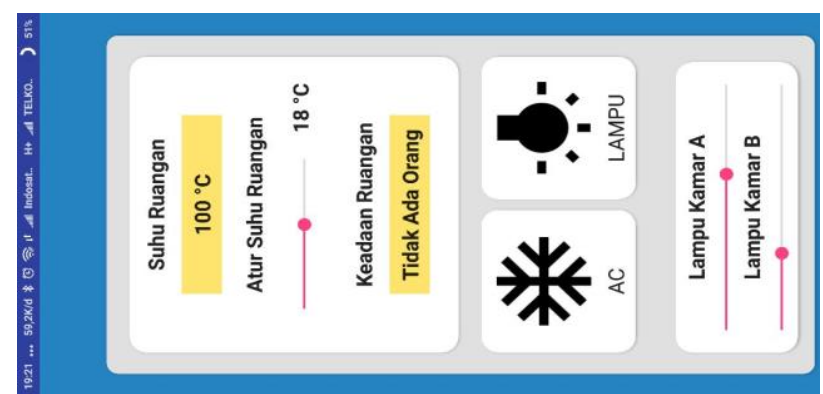

Gambar 2. Desain Kontroler berbasis android

F. Thingspeak : A IoT Web Services

Thingspeak merupakan web berbasis open API IOT source platform informasi yang komprehensif dalam menyimpan data sensor dari 'aplikasi IOT' bervariasi dan berkonspirasi, data output yang dihasilkan dalam bentuk grafik di tingkat web. Thingspeak berkomunikasi dengan bantuan koneksi internet yang bertindak sebagai 'paket data' pembawa antara 'hal/benda (sensor)' yang saling terhubung dan Thingspeak mengambil, menyimpan, menganalisis, mengamati dan bekerja pada data yang dirasakan dari sensor yang terhubung ke mikrokontroler seperti 'Arduino, modul TI CC3200, Raspberry-pi dll [4].
Berikutnya adalah prototipe produk yang dihasilkan yang di rancang menyerupai ruangan di dalam rumah yag terdiri dari 4 lampu. Dapat dilihat pada Gambar 3.

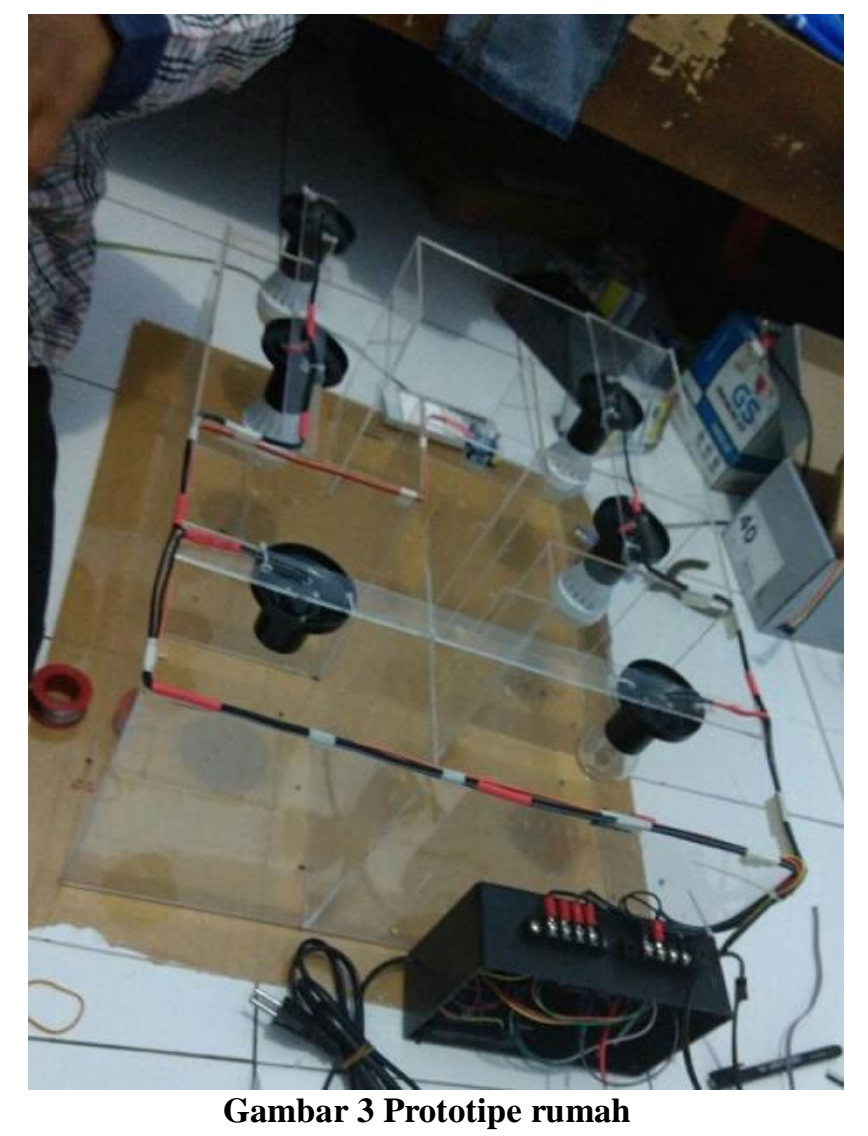

G. Flowchart Sistem Kendali

Diagram alir (flowchart) sistem pada sistem kendali jarak jauh berbasis arduino menggunakan modul wifi esp8266 pada aplikasi internet of thing dapat dilihat pada gambar 4 


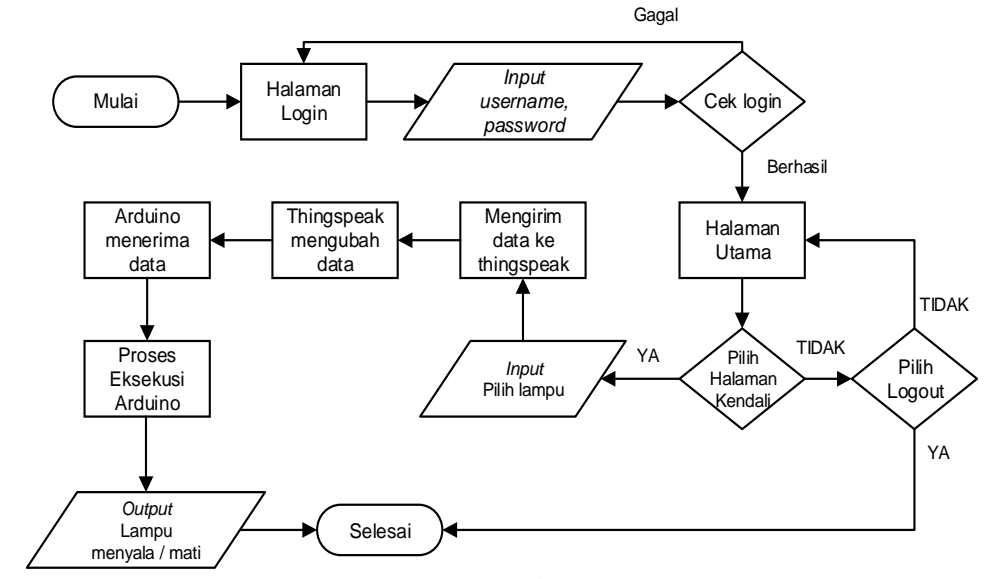

Gambar 4 Flowchart Sistem Kendali

H. Implementasi sistem merupakan dimana sebuah sistem yang telah di buat sebelumnya sudah bisa digunakan. Bab ini merupakan hasil akhir dalam pembuatan sebuah sistem kendali jarak jauh [5]. Berikut ini adalah penggunaan program beserta fasilitas-fasilitas yang disediakan dalam sistem.

1. Halaman Login

Halaman Login merupakan halaman awal ketika mengakses alamat website dan berfungsi untuk menjaga keamanan sistem.

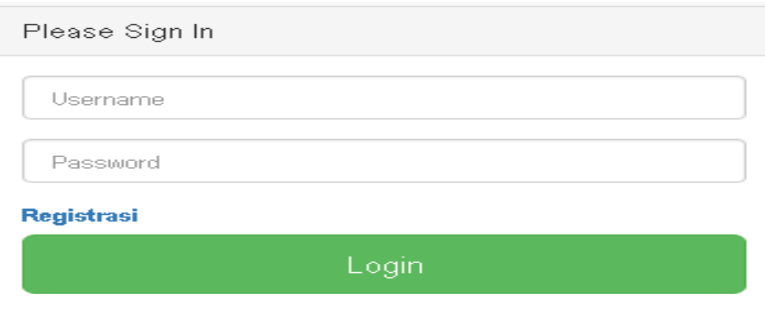

Gambar 5 Halaman Login

Pengujian yang dilakukan yaitu untuk mengetahui kinerja dari alat pengendali jarak jauh pada penerapan teknologi internet of things. Pengujian dilakukan untuk mengetahui perbedaan waktu atau waktu yang dibutuhkan pengguna dari memberikan perintah dari web yang sudah dibuat sampai dengan lampu menyala atau mati. Pengujian ini dilakukan dengan beberapa koneksi internet seperti $3 \mathrm{G}$ dan $4 \mathrm{G}$.

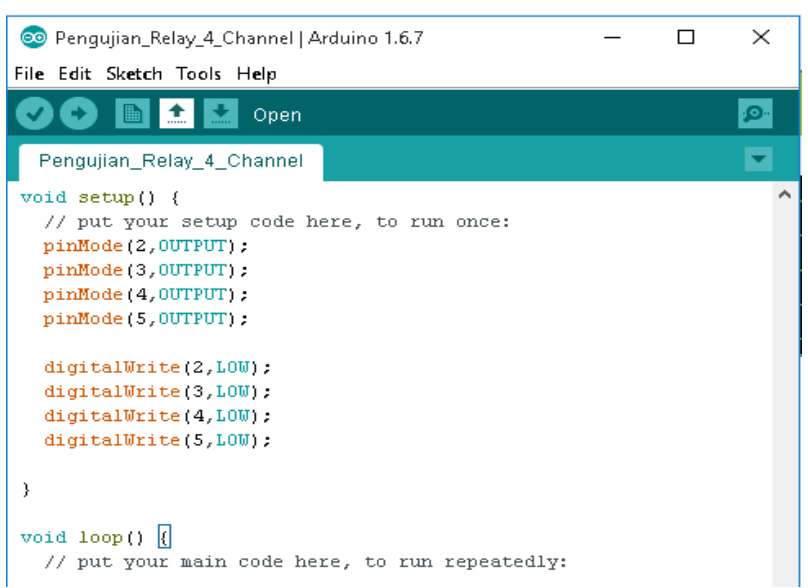

Gambar 6 Kode Program Pengujian Modul Relay
Tabel 1 Relay

\begin{tabular}{|c|l|c|c|l|}
\hline No & $\begin{array}{c}\text { Name } \\
\text { Field }\end{array}$ & $\begin{array}{c}\text { Tipe } \\
\text { Data }\end{array}$ & Len & Keterangan \\
\hline 1 & Id & Int & 11 & $\begin{array}{l}\text { Nomor identitas } \\
\text { relay (Auto } \\
\text { Increment })\end{array}$ \\
\hline 2 & time & datetime & & $\begin{array}{l}\text { Tanggal dan } \\
\text { Waktu }\end{array}$ \\
\hline 3 & field1 & char & 1 & Relay 1 \\
\hline 4 & field2 & char & 1 & Relay 2 \\
\hline 5 & field3 & char & 1 & Relay 3 \\
\hline 6 & field4 & char & 1 & Relay 4 \\
\hline 7 & id_ts & Int & 11 & $\begin{array}{l}\text { Nomor Identitas } \\
\text { Thingspeak }\end{array}$ \\
\hline
\end{tabular}

\section{Pengujian Kinerja Alat}

Pengujian Arduino UNO merupakan pengujian yang dilakukan untuk mengetahui tegangan pada setiap pin yang ada pada Arduino UNO. Arduino UNO diberi tegangan input sebesar 5 volt dan pin output diukur menggunakan multimeter. Pengujian pada pin Arduino dilakukan dengan memberikan logika HIGH dari pin $0-$ 13 dan pin A0 - A5. Pengujian pin output Arduino UNO didapatkan hasil tegangan sebesar 4,8 Volt. Hasil ini mendekati tegangan operasi yaitu sebesar 5 Volt.

2. Modul WiFi ESP8266 - 01

Pengujian modul WiFi ESP8266 - 01 dilakukan dengan cara memberikan tegangan sebesar 3,3 volt. Catu daya yang diberikan tidak dari pin 3,3 volt Arduino melainkan menggunakan catu daya terpisah sehingga membutuhkan voltage regulator 1117 . Voltage regulator yang digunakan yaitu AMS1117-3,3. Pin Rx dan Tx Arduino dihubungkan dengan pin Rx dan Tx pada ESP8266 - 01 dapat dilihat pada gambar 7 .

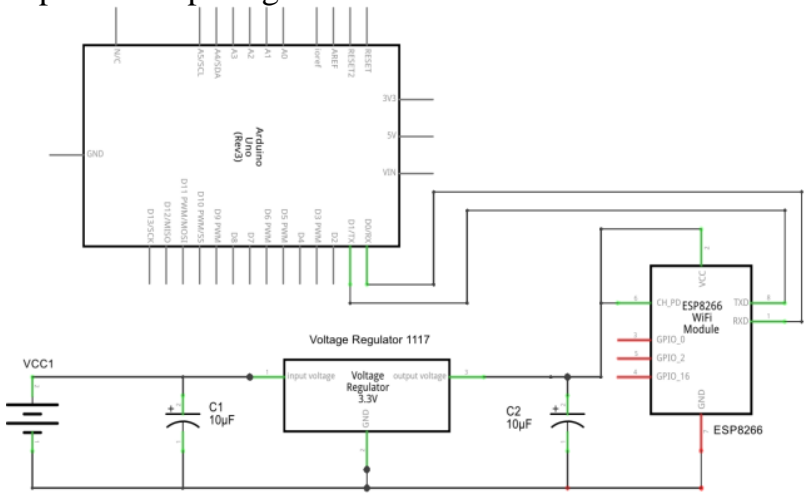

Gambar 7 Rangkaian Pengujian Modul ESP8266 - 01

Pengaturan awal modul Esp8266 untuk menjadikan Access Point dengan perintah AT Command "AT $+\mathrm{CWMODE}=2$ " pada serial monitor kemudian, dengan menggunakan smartphone atau laptop untuk mendeteksi dan menghubungkan wifi pada modul Esp8266 - 01. Pengujian modul wifi esp8255 - 01 menunjukan bahwa modul terdeteksi dan dapat terhubung dengan baik.

Dalam penelitian ini, diperlukan pergantian firmware 0x00000 dan 0x40000 dengan cara melakukan flashing 
pada modul esp8266 - 01. Flashing dilakukan dengan menggunakan Arduino UNO dan tools flashing. Sebelum melakukan flashing, adapun kode program yang harus di upload ke mikrokontroler yang dapat dilihat pada gambar 8

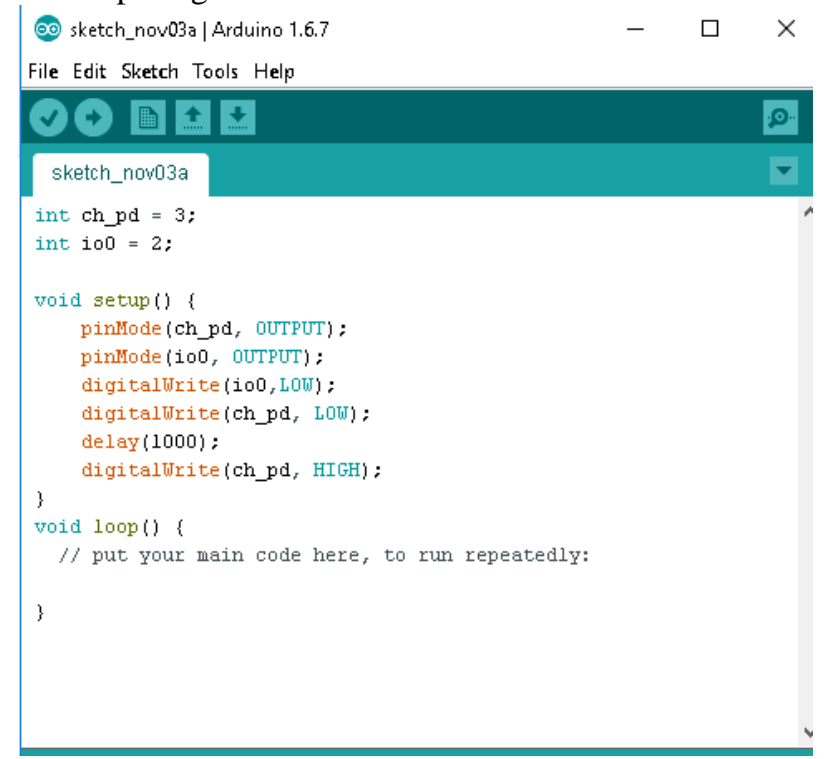

Gambar 8 Kode Program Flashing ESP8266 - 01

Pengujian kinerja alat yaitu untuk mengetahui waktu yang dibutuhkan atau waktu eksekusi dengan membandingkan jaringan $3 \mathrm{G}$ dan $4 \mathrm{G}$. Pengujian ini membutuhkan satu modul untuk menunjukan waktu ketika lampu menyala atau mati. Modul yang digunakan yaitu Real Time Clock DS3231. Real Time Clock(RTC) DS3231 dapat berfungsi untuk menyimpan waktu yang sebelumnya sudah di setting terlebih dahulu, sehingga pada saat pengujian tidak perlu melakukan setting untuk mengatur waktu agar dapat menampilkan waktu ketika lampu menyala.

Diketahui bahwa sistem kendali jarak jauh ini menggunakan media web sebagai kendali atau kontrol untuk memberikan perintah ke Arduino UNO sehingga, untuk mengetahui waktu yang dibutuhkan hingga lampu menyala atau mati dapat dilihat dari waktu yang disimpan pada database server web hosting, waktu update pada server api.thingspeak.com, dan waktu yang ditampilkan pada serial monitor Arduino IDE ketika lampu menyala atau mati. Pengujian dilakukan sebanyak 10 kali kemudian akan dicari rata-rata waktu eksekusi setiap pengujian, sehingga didapatkan rumus untuk mencari rata - rata waktu yang ditunjukan dalam satuan detik.

Rumus :

$\mathrm{R}=(\mathrm{L} 1-\mathrm{DS})+(\mathrm{L} 1-\mathrm{DS})+(\mathrm{L} 3-\mathrm{DS})+(\mathrm{L} 4-\mathrm{DS}) / 4$

$\mathrm{R}=$ Rata-rata waktu eksekusi

DS = Waktu pada database server

L1 = Waktu lampu 1

L2 = Waktu lampu 2

L3 = Waktu lampu 3

L4 = Waktu lampu 4

Pengujian output dilakukan dengan menggunakan web yang sudah dibuat untuk mengetahui apakah alat sudah berfungsi dengan baik untuk penerapan internet of things. Hasil pengujian dapat dilihat pada tabel 2

Hasil pengujian modul relay 4 channel dapat dilihat pada tabel 2.

Tabel 2 Pengujian Saklar

\begin{tabular}{|c|c|l|l|} 
No & Unit & Perintah & \multicolumn{1}{|c|}{ Hasil } \\
\hline 1 & $\begin{array}{c}\text { Relay 1 } \\
\text { (Lampu 1) }\end{array}$ & $\begin{array}{l}\text { ON } \\
\text { OFF }\end{array}$ & $\begin{array}{l}\text { Menyala } \\
\text { Mati }\end{array}$ \\
\hline 2 & $\begin{array}{c}\text { Relay 2 } \\
\text { (Lampu 2) }\end{array}$ & $\begin{array}{l}\text { ON } \\
\text { OFF }\end{array}$ & $\begin{array}{l}\text { Menyala } \\
\text { Mati }\end{array}$ \\
\hline 3 & $\begin{array}{c}\text { Relay 3 } \\
\text { (Lampu 3) }\end{array}$ & $\begin{array}{l}\text { ON } \\
\text { OFF }\end{array}$ & $\begin{array}{l}\text { Menyala } \\
\text { Mati }\end{array}$ \\
\hline 4 & $\begin{array}{c}\text { Relay 4 } \\
\text { (Lampu 4) }\end{array}$ & $\begin{array}{l}\text { ON } \\
\text { OFF }\end{array}$ & $\begin{array}{l}\text { Menyala } \\
\text { Mati }\end{array}$ \\
\hline
\end{tabular}

Hasil pengujian dari relay menunjukkan bahwa .modul relay 4 channel berfungsi dengan baik.

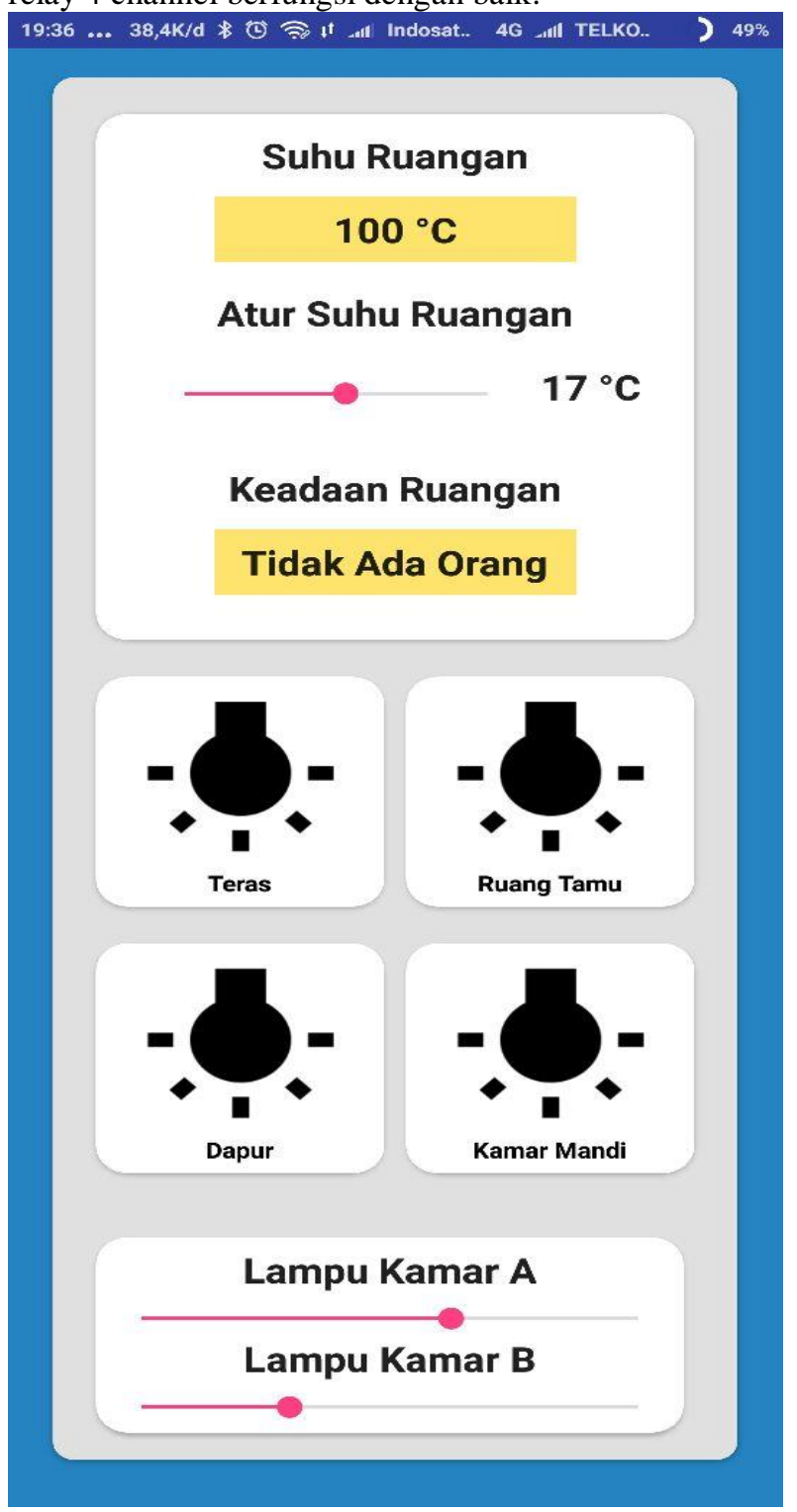

Gambar 9 Antar Muka Android sebagai Saklar 


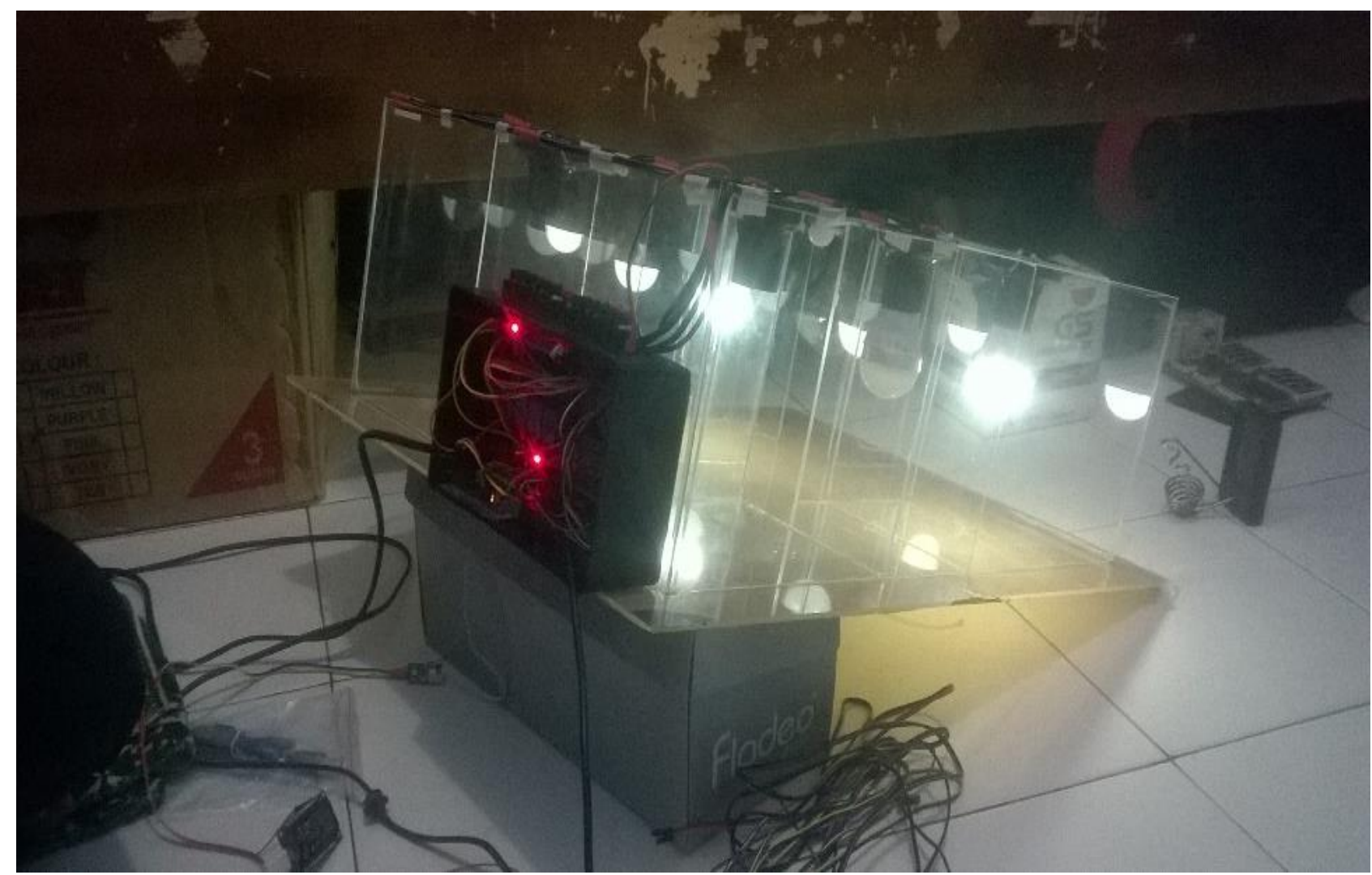

Gambar 10 Pengujian Penyalaan Lampu

\section{Kesimpulan}

Berdasarkan hasil perancangan dan hasil pengujian dari sistem kendali jarak jauh berbasis Arduino dengan menggunkan modul wifi ESP8266 pada aplikasi internet of things dapat disimpulkan sebagai berikut :

1. Rangkaian alat terdiri dari Arduino UNO, modul wifi ESP8266 versi 01, dan modul relay 4 channel sebagai saklar otomatis untuk memutus atau menyambungkan aliran listrik ke lampu.

2. Rangkaian ditambahkan dengan modul real time clock DS3231 yang berfungsi untuk membantu menghitung waktu eksekusi dari data yang tersimpan ke database server hingga lampu menyala atau mati

Saran

Dalam pembuatan alat ini berdasarkan dari penerapan teknologi internet of things masih banyak terdapat kekurangan. Saran yang dapat disampaikan untuk peneliti selanjutnya yaitu :

Program yang ditanamkan pada Arduino membutuhkan pengulangan (looping) untuk mendapatkan data dari Thingspeak, sehingga dapat menyebabkan penggunaan paket data yang berlebihan. Peneliti berikutnya dapat memperbaiki alat, sehingga alat dapat bekerja tanpa harus melakukan pengulangan dalam mengambil atau menerima data dari Thingspeak

3. Cuplikan

Dalam pembuatan jurnal ini, penulis menyampaikan banyak terimakasih kepada Kementrian Ristekdikti yang telah membiayai sehingga penelitian ini dapat dilakukan dan berjalan sesuai dengan yang direncanakan.

\section{DAFTAR PUSTAKA}

[1] Sulistyanto, M. T., Nugraha, D. A., dkk. (2015). Implementasi IoT (Internet of Things) dalam pembelajaran di Universitas Kanjuruhan Malang. SMARTICS Journal, 1(1), 20-23.

[2] Alamsyah, Ardi, A., \& Faisal, M. N. (2015). Perancangan dan Penerapan Sistem Kontrol Peralatan Elektronik Jarak Jauh Berbasis Web. Jurnal Mekanikal, 6(2), 577-584.

[3] Giyartono, A., \& Kresnha, P. E. (2015). Aplikasi Android Pengendali Lampu Rumah Berbasis Mikrokontroler ATmega328. Seminar Nasional Sains dan Teknologi 2015, pp. 1-9.

[4] Pasha, S.(2016).Thingspeak Basic Sensing and Monitoring System for IoT with Matlab Analisis.International Journal of New Technology and Research(IJNTR) .2(6).19-23.

[5] Luitel, S.2013. Design and Implementation of a Smart Home System.Tesis. Degree Programme Information Technology, Helsinki Metropolia University of Apllied Science.Helsinki, Finlandia.

[6] Zanella, A., \& Vangelista, L..Internet of Things for Smart Cities. IEEE INTERNET OF THINGS JOURNAL, 1(1), 22-32. 